\title{
Arterial Hypertension in a Child with Williams-Beuren Syndrome (7q11.23 Chromosomal Deletion)
}

\author{
Cristina de Sylos, Alexandre C. Pereira, Estela Azeka, Nana Miura, \\ Sônia Maria Ferreira Mesquita, Munir Ebaid \\ São Paulo, SP - Brazil
}

\begin{abstract}
We report the case of a 7-year-old male child diagnosed with Williams-Beuren syndrome and arterial hypertension refractory to clinical treatment. The diagnosis was confirmed by genetic study. Narrowing of the descending aorta and stenosis of the renal arteries were also diagnosed. Systemic vascular alterations caused by deletion of the elastin gene may occur early in individuals with Williams-Beuren syndrome, leading to the clinical manifestation of systemic arterial hypertension refractory to drug treatment.
\end{abstract}

The Williams-Beuren syndrome, a rare congenital anomaly involving the vascular system, connective tissue, and central nervous system, was initially described by Williams et al in 1961, and then by Beuren in 1962. In 1993, Ewart attributed the etiology of the syndrome to a microdeletion involving the elastin gene in chromosome $7^{1,2}$.

Cardiac anomalies are present in approximately $70 \%$ of the cases, aortic supravalvular stenosis being the most frequent, followed by peripheral stenosis of the pulmonary arteries, and, more rarely, by mitral insufficiency, coarctation of the aorta, and ventricular septal defect ${ }^{3,4}$.

Arterial hypertension occurs in 1/3 of the cases, being associated with coarctation of the aorta, stenosis of the renal artery, arteriopathy, nephrocalcinosis, and renal malformations, such as renal aplasia, hypoplasia, dystopia, renal duplication, cysts and diverticula of the bladder ${ }^{5-7}$.

We report the case of a child with Williams-Beuren syndrome confirmed by genetic study with the polymerase chain reaction and research of heterozygosity loss in the microdeletion region of chromosome 7 . The patient had systemic arterial hypertension detected at school age.

Instituto do Coração do Hospital das Clínicas - FMUSP Mailing address: Cristina de Sylos - InCor - Av. Dr. Enéas C. Aguiar, 44 - 05403-000 São Paulo, SP, Brazil - e-mail: crsylos@netpoint.com.br English version by Stela Maris C. e Gandour

\section{Case Report}

The patient was a 7-year-old male child born from a secundipara mother. A cardiac murmur was diagnosed at birth, and the patient was on clinical follow-up due to minimum muscular interventricular defect, evolving with good ponderal development, mild cognitive delay, hyperactivity, syndromic facies, and normal karyotype. No other investigation was performed until the age of 7 years, when, on a routine pediatric medical visit, systemic arterial hypertension was detected $(200 / 130 \mathrm{mmHg})$. After evidencing normal renal and electrolytic functions, antihypertensive medication (captopril, propranolol, chlorthalidone) was started. As the patient remained with refractory systemic arterial hypertension, he was referred to the pediatric cardiology service of the Instituto do Coração (InCor-HCFMUSP), where, with the association of amlodipine to the previous medication, blood pressure levels could be better controlled.

On clinical examination at hospital admission, the patient was in good general condition. His weight was $25.40 \mathrm{~kg}$, his height was $1.23 \mathrm{~m}$, his blood pressure was $150 / 100 \mathrm{mmHg}$ in the right upper limb and 140/90 $\mathrm{mmHg}$ in the remaining limbs, and his heart rate was $90 \mathrm{bpm}$. The patient had symmetric pulses, a peculiar facies, excessive periorbital subcutaneous cellular tissue, hypertelorism, saddle nose, thick lips, and wide and half-open mouth with separated teeth (fig. 1). On cardiovascular examination, a moderate systolic murmur $(++/ 4+)$ could be heard on the infraclavicular region, bilaterally, and on the left sternal margin irradiating to the dorsum. The abdomen had no palpable masses, but a low systolic-diastolic murmur could be heard on the left flank. In the feet, syndactyly between the $2^{\text {nd }}$ and $3^{\text {rd }}$ and between the $3^{\text {rd }}$ and the $4^{\text {th }}$ toes was observed with hypoplasia of the $5^{\text {th }}$ toe. Diagnostic investigation proceeded with the genetic test for detecting the characteristically deleted region in Williams-Beuren syndrome, which evidenced microdeletion in the $7 \mathrm{q} 11.23$ chromosomal region(fig. 2).

On chest X-rays, a mild enlargement of the cardiac area due to the left ventricle was evidenced. Electrocardiography showed biventricular hypertrophy and vectorcardiography suggested right ventricular hypertrophy. Echo- 


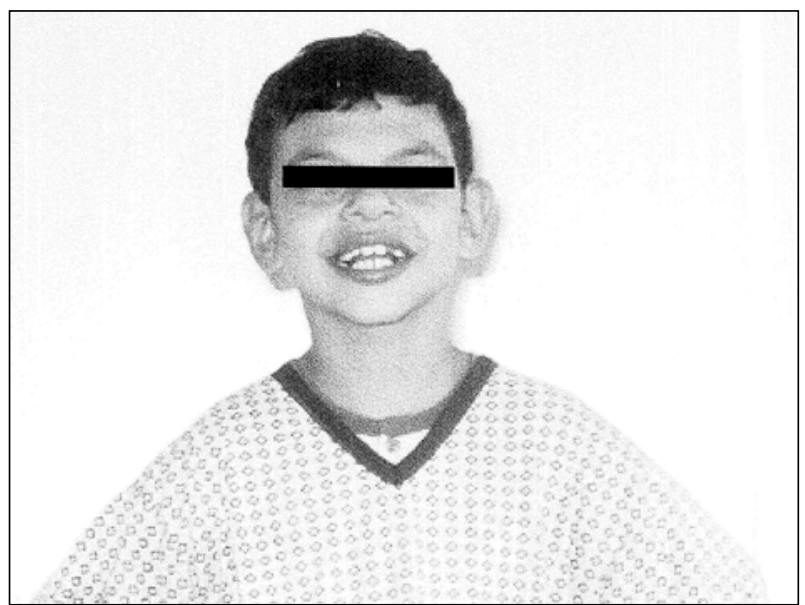

Fig. 1 - Typical facial characteristics of a patient with Williams-Beuren syndrome. Hypertelorism, saddle nose, excessive periorbital tissue, thick lips, and half-open mouth. MSC, 6 years, 2000.

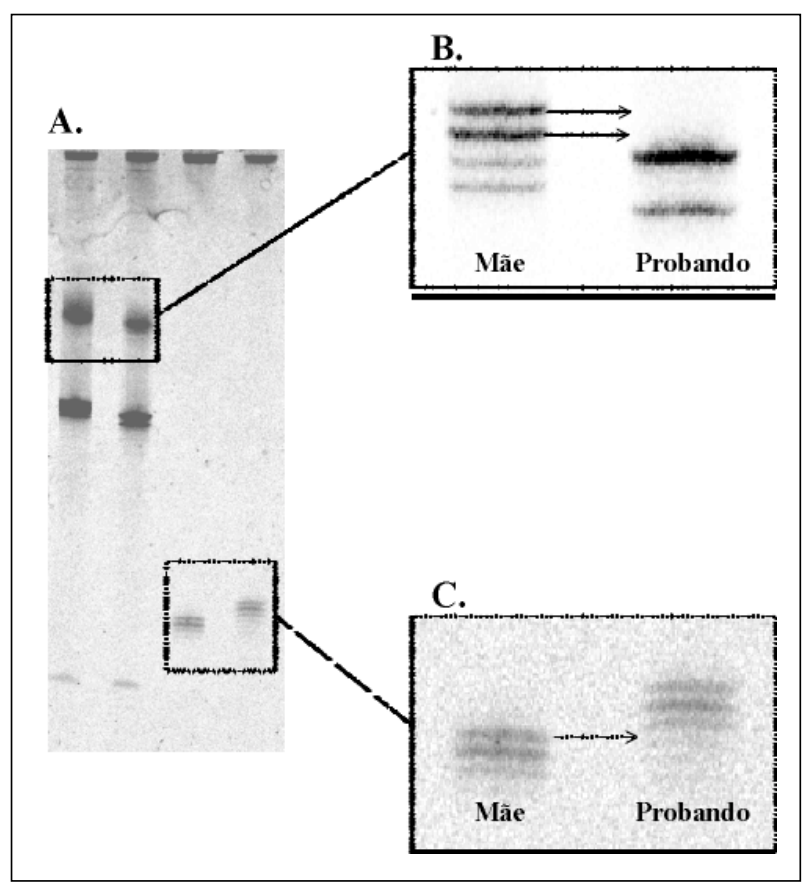

Fig. 2 - Diagnostic test for microdeletion in 7q11.23. A) Overview of the polymorphic markers located in the commonly deleted region of chromosome 7. In this figure, alleles present in the patient and his mother are shown; B) detail of the Hei marker, in which the patient studied (proband) showed none of the his mother's alleles (deleted); C) detail of the D7S1870 marker, with none of the mother's alleles in the proband, defining the diagnosis of microdeletion in the region studied. MSC, 6 years, 2000.

cardiography showed interventricular muscular septal defect of $4 \mathrm{~mm}$ with no hemodynamic repercussion, and pulmonary arteries of equal caliber $(17 \mathrm{~mm})$. Magnetic resonance imaging showed narrowing of the descending aorta with the following aortic measurements: in the ascending portion $-13 \mathrm{~mm}$, in the descending portion -10 to $11 \mathrm{~mm}$, in the abdominal region $-8 \mathrm{~mm}$, and in the renal region $-5 \mathrm{~mm}$. The renal arteries showed segmentary stenosis in their initial portion, celiac trunk with significant stenosis, and left pulmonary artery caliber slightly smaller than that of the right pulmonary artery. The interventional catheterization (fig. 3) performed for angioplasty of the renal artery evidenced progressive narrowing of the aorta, stenosis of the right renal artery, and obstruction of the left renal artery with collaterals. Dynamic renal scintigraphy showed a markedly depressed glomerular function in the left side and preserved in the right side, with an $85 \%$ function in the right kidney and $15 \%$ function in the left kidney.

\section{Discussion}

Williams-Beuren syndrome is a rare genetic condition, with an incidence of 1:20,000 live births and sporadic occurrence in most cases, despite reports of familial recurrence with dominant autosomal inheritance and variable penetrance ${ }^{8}$.

In 1993, Ewart et al ${ }^{9}$ identified a haploinsufficiency of genes located in the 7q11.23 chromosomal band associated with the syndrome. This deletion, studied with FISH and molecular biology, has approximately 2.5 to $3.5 \mathrm{Mb}$ and includes genes, such as the elastin gene (ELN), LIMK1, RFC2, FZD3, WBSCR1, STX1A, and other units of unknown function. This variation in genetic deletion is partly responsible for the variation in the degree of severity of the syndrome, and at least one of the markers may be found in $96 \%$ of the cases clinically diagnosed ${ }^{10}$. The present case was studied with markers for the elastin gene through the polymerase chain reaction with comparative samples of the parents and child, and the diagnosis was confirmed (fig. 2).

Clinically, the patients have a neonatal history of low ponderal gain, frequent crying, difficulty in sleeping, and intestinal constipation with rectal prolapse. Inguinal hernias occur in $1 / 3$ of the cases. Idiopathic hypercalcemia occurs in some children, is probably related to a deficiency in calcitonin, and may be spontaneously resolved around the age of 18 to 24 months ${ }^{11}$. The face is characterized by saddle nose and wide nostrils, wide mouth with prominent lips, the lower one being preponderant, periorbital effusion, epicanthus, and frequent star-shaped iris. Hyperacusia is present in $50 \%$ of cases, mental deficiency is of variable degree, microcephaly is present in $1 / 3$ of the cases, and the patients are almost always communicative and sociable. These are the characteristics that lead to diagnostic suspicion ${ }^{12-14}$. In our case, we observed facial and behavioral characteristics typical of the syndrome.

Cardiovascular alterations are frequently found, in approximately $70 \%$ of the cases, aortic supravalvular stenosis being the most common association, $75 \%$ of the cases, followed by stenosis of the pulmonary branches. Few patients have a combination of both anomalies. Other cardiac anomalies associated include mitral insufficiency, coarctation of the aorta, ventricular septal defect, and arrhythmias $5,7,8$. Our patient had diffuse narrowing of the aorta and its branches, and obstruction of the renal artery with a reduction in renal perfusion, in addition to ventricular septal defect. No aortic supravalvular stenosis or stenosis of the peripheral pulmonary branches was observed.

Arteriopathy is rare, generalized, with a marked and 


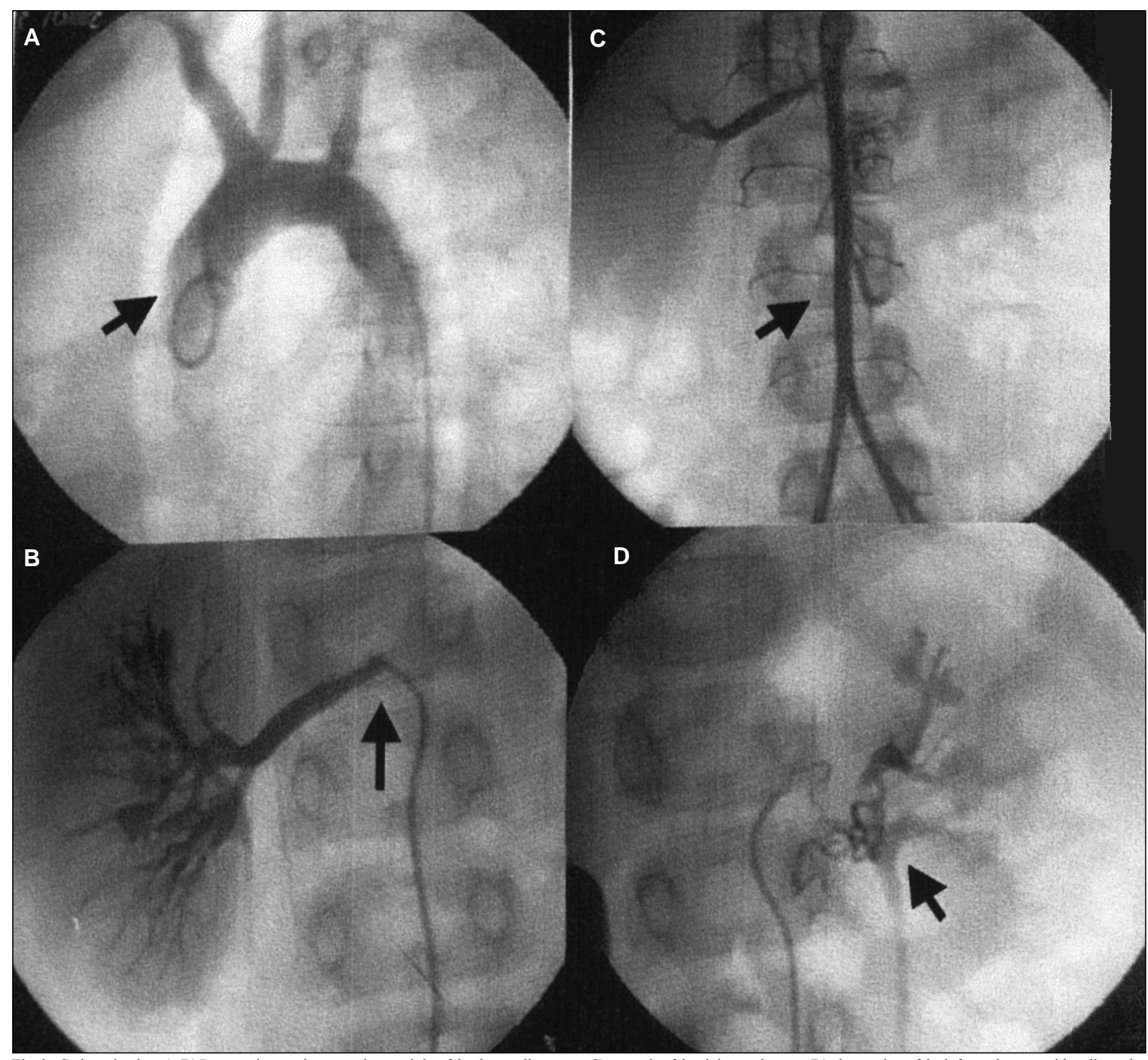

Fig. 3 - Catheterization. A, B) Progressive aortic narrowing, mainly of the descending aorta; C) stenosis of the right renal artery; D) obstruction of the left renal artery with collaterals. MSC, 6 years, 2000.

progressive narrowing of the lumen, resulting in obstruction of the left ventricular outflow tract, reduction in the pulmonary flow, systemic arterial hypertension, and impairment of organ perfusion. Progressive stenosis of the aorta and its branches (renal, mesenteric, coronary, and cerebral arteries) has been reported, as have been cerebrovascular stroke and sudden death due to myocardial infarction ${ }^{15}$. The presence of narrowing of the abdominal aorta and stenosis of its major branches have been reported rarely in Williams syndrome, and Bliddal et al ${ }^{16}$, in 1969 , were the first to observe that association. Pangiotopoulos et al ${ }^{17}$ reported 3 patients with Williams syndrome of a total of 13 patients with that arteriopathy.

Arterial hypertension has been reported in $40 \%$ to $70 \%$ of the cases, few of which being refractory to medication, and it has been associated with coarctation of the aor- ta, nephropathy due to nephrocalcinosis or renal insufficiency, and diffuse arteriopathy, like that of the case reported.

Renal anomalies are present in up to $17.7 \%$ of the cases, which is an incidence significantly greater than that found in the general population (1.5\%), and those anomalies may be cystic, with hydronephrosis, agenesis, hypoplasia, reflux, diverticula, nephrocalcinosis, and ischemia ${ }^{18-21}$.

Stenosis of the renal artery has been reported in a few cases, $1 \%$ in the 40 patients studied by Pober et al ${ }^{22}$, and $6.2 \%$ in the study by Pankau et al ${ }^{23}$. Stenosis of the renal artery is sometimes bilateral and associated with renovascular hypertension and renal insufficiency, the latter also of rare occurrence and varied etiology. The diagnosis may be established on Doppler ultrasound, angiography, spiral tomography, postcaptopril renography, and magnetic resonance imaging, the latter, when performed with contrast medium, shows 
sensitivity and specificity of almost $100 \%{ }^{24-27}$. In our patient, the diagnosis was established with magnetic resonance imaging during investigation of coarctation of aorta. In addition to the diffuse and progressive narrowing of the descending aorta, we observed stenosis of the right renal artery and total obstruction of the left renal artery, the renal irrigation provided only by collaterals, which led to a great renal functional deficit, confirmed on perfusion scintigraphy.

The progressive advances on molecular biology have provided us with detailed knowledge about the etiology and evolution of some diseases. In Williams syndrome, this is evidenced in the association of genes and certain clinical findings, such as the elastin gene associated with diffuse vascular alterations.

Cardiovascular abnormalities associated with the syndrome still lack characterization in regard to incidence and evolution. Routine investigation and evolution follow-up of other cardiovascular abnormalities other than the most frequent aortic supravalvular stenosis and stenosis of the pulmonary artery branches are not frequently found in the follow-up of patients with Williams syndrome.

Williams-Beuren syndrome is a progressive vascular disease with progressive impairment of the kidneys and other organs, such as the central nervous system, heart, and lungs, and, according to Miyamura et al ${ }^{28}$, should be assessed considering the need and value of interventions reported the cases of adolescent patients with Williams syndrome who evolved with spontaneous regression of the peripheral pulmonary artery stenosis, and other authors ${ }^{29-32}$ reported the cases of adult olygosymptomatic patients with late diagnosis, but with renal (renal insufficiency), cardiac, and peripheral complications.

The treatment of stenosis of the renal artery performed with splenorenal bypass has a good evolution ${ }^{33}$, and was the treatment proposed for this patient with arterial hypertension refractory to clinical treatment and left renal impairment. The patient evolved uneventfully in the postoperative period, and a reduction in blood pressure levels was observed at a 3-month follow-up.

In conclusion, systemic arterial hypertension in a patient with Williams-Beuren syndrome may manifest later at school age and may be secondary to diffuse arterial disease with impairment of the renal arteries. Assessing systemic arterial hypertension in patients with Williams-Beuren syndrome is paramount, even though this is usually valued little in these patients' follow-up.

\section{References}

1. Joyce CA, Zorich B, Pike SJ, Barber JC, Dennis NR. Williams Beuren syndrome: phenotypic variability and deletions of chromossomes 7,11, and 22 in a series of 52 patients. J Med Genet 1996; 33: 986-92.

2. Jurado LAP, Wang Y, Peoples R, Coloma A, Cruces J, Francke U. A duplicated gene in the breakpoint regions of the 7q11.23 Williams Beuren syndrome deletion encodes the initiator binding protein TFII-I and BAP-135, a phosphorylation target of BTK. Hum Mol Genet 1998; 7: 325-34.

3. KotzotD, Bernasconi F, Brecevis L, et al. Phenotype of the Williams-Beuren syndrome associated with hemizygosity at the elastin locus. Eur J Pediatr 1995; 154: 477-82.

4. Metcalfe K. Williams syndrome: an update on clinical and molecular aspects. Arch Dis Child 1999; 81: 198-200.

5. Daniels SR, Loggie JM, Schwartz DC, Strife JL, Kaplan S. Systemic hypertension secundary to peripheral vascular anomalies in patients with Williams syndrome. J Pediatr 1885; 106: 249-51.

6. Suzuki Y, Shimazaki S, Kaneko K, Ino K, Yabuta K. Renal abnormalities associated with Williams syndrome. J Pediatr 1992; 121: 667.

7. Ounap K, Laidre P, Bartsch O, Rein R, Lipping-Sitska M. Familial Williams-Beuren syndrome. Am J Med Genet 1998; 28; 80: 491-3.

8. Vilches O, Rubio Cuadrado MV, Martinez J, Lopez AG. William's syndrome: report a case with familial envolviment. Rev Clin Esp 1998; 198: 91-4.

9. Ewart Ak, Morris CA, Atkinson D, et al. Hemizygosity at the elastin locus in a developmental disorder, Williams syndrome. Nat Genet 1993; 5: 11-16.

10. Pena S. Molecular cytogenetics II: PCR-based diagnosis of chromosomal deletions and microdeletion syndromes. Genet Molec Biol 1998; 21: 453-60.

11. Culler F, Jones KL, Deftos LJ. Impaired calcitonin secretion in patients with Williams syndrome. J Pediatr 1985; 107: 720-3.

12. Pankau R, Partsch CJ, Gosch A, Winter M, Wessel A. Picture of the month. William-Beuren syndrome. Arch Pediatr Adolesc Med 1997; 151: 203-4.

13 Brondum-Nielsen K, Beck B, Gyftodimou J, et al. Investigation of deletions at $7 q 11.23$ in 44 patients referred for Williams-Beuren syndrome, using FISH and four DNA polymorphisms. Hum Genet 1997; 99: 56-61.

14. Brinkmann G, Heller M, Partsch CJ, Gosh A, Pankau R. Magnetic resonance imaging of the brain in Williams-Beuren syndrome. Am J Med Gent 1997; 68: 243.

15. Bonnet D, Cormier V, Villain E, Bonhoeffer P, Kachaner J. Progressive left main coronary artery obstruction leading to myocardial infarction in a child with Williams syndrome. Eur J Pediatr 1997; 156: 751-3.

16. Bliddal J, Dupont B, Melchior JC, Ottesen OE. Coarctation of the aorta with multiple artery anomalies in idiopathic hypercalcemia of infancy. Acta Paediatr Scand 1969; 58: 632-7.
17. Panayiotopoulos YP, Tyrrell MR, Koffman G, Reidy JF, Haycock GB, Taylor PR Mid-aortic syndrome presenting in childhood. Br J Surg 1996; 83: 235-40.

18. Steiger MJ, Rowe PA, Innes A, Burden RP. Williams syndrome and renal failure. Lancet 1998; 2 (8614): 804.

19. Fischbach M, Lutz JD, Tongio J, Sauvage, Geiser J, Levy JM. Williams-Beuren's syndrome with hypertension and associate renal abnormalities. Sem Hop 1979; 8-15(13-14): 689-93.

20. Chalmers RT, Dhadwal A, Deal JE, Sever PS, Wolfe JH. The surgical management of renovascular hypertension in children and young adults. Eur J Vasc Endovasc Surg 2000; 19: 400-5.

21. Poulias GE, Skoutas B, Doundoulakis N, et al. The mid-aortic dysplasic syndrome. Surgical considerations with a 2 to 18 year follow-up and selective histopathological study. Eur J Vasc Surg 1990; 4: 75-82.

22. Pober BR, Lacro RV, Rice C, Mandell V, Teele RL. Renal findings in 40 individuals with Williams syndrome. Am J Med Genet 1993; 46: 271-4.

23. Pankau R, Partsch CJ, Winter M, Gosch A, Wessel A. Incidence and spectrum of renal abnormalities in Williams-Beuren syndrome. Am J Medic Genet 1996; 63: $301-4$

24. Ino T, Nishimoto K, Iwahara M, et al. Progressive vascular lesions in Williams syndrome. J Pediatr 1985; 107: 826.

25. Adams WM, John PR. US demonstration and diagnosis of the midaortic syndrome. Pediatr Radiol 1998; 28: 461-3.

26. Elkohen M. Screening of renal artery stenosis: wich patients, by what methods? Ver Prat 1996; 46: 1091-5.

27. Silverman JM, Friedman ML, Van Allan RJ. Detection of main renal artery stenosis using phase-contrast MR angiography. Am J Roentgenol 1996; 166: 1131-7.

28. Miyamura H, Watanabe H, Tabete S, Eguchi S. Spontaneous regression of peripheral pulmonary arterial stenosis in Williams syndrome. Jpn Circ J 1996; 60: 311-4.

29. Ichinose M, Tojo K, Nakamura H, et al. Williams syndrome associated with chronic renal failure and various endocrinological abnormalities. Intern Med 1996; 35: 482-8.

30. Biesecker LG, Laxova R, Friedman A. Renal insufficiency in Williams Syndrome Am J Med Genet 1987; 28: 131-5.

31. Matsumoto A, Nitta M, Niwa A, et al. Williams syndrome: a middle-aged case of markedly delayed diagnosis. Jpn Heart J 1993; 34: 653-9.

32. Nicholson WR, Hockey KA. Williams syndrome: a clinical study of children and adults. J Paediatr Child Health 1993; 29: 468-72.

33. Khauli RB, Novick AC, Ziegelbaum M. Splenorenal bypass in the treatment of renal artery stenosis: experience with sixty-nine cases. J Vasc Surg 1985; 2: 547-51. 